\title{
DETERMINACIÓN DEL SEXO FETAL EN EL PRIMER TRIMESTRE DE LA GESTACIÓN: ESTUDIO PROSPECTIVO
}

\author{
Begoña Adiego Burgos ${ }^{1}$, Pilar Martínez Ten ${ }^{1}$, Javier Pérez Pedregosa ${ }^{1}$, Alicia Crespo \\ Rivera ${ }^{1}$, Belén Santacruz Martín ${ }^{1}$, Tamara Illescas Molina ${ }^{1}$, Esther Barrón Azurmendi ${ }^{1}$. \\ 1 Delta Ecografía, Madrid, España.
}

\section{RESUMEN}

Objetivos: Valorar la precisión de la determinación ecográfíca del sexo fetal entre las 11 y las 14 semanas en una cohorte no seleccionada de gestantes. Métodos: Se realizó un estudio prospectivo transversal en una serie consecutiva de 636 gestaciones entre las 11 y 14 semanas, en gestantes que acudieron para el estudio ecográfico rutinario de primer trimestre. Se examinó la región genital del feto en un plano mediosagital, visualizando el "signo sagital" y la dirección en la que apunta el tubérculo genital (craneal en los varones, caudal en las mujeres) ambos indicadores del sexo fetal. La confirmación clínica del sexo fetal se obtuvo después del parto por confirmación telefónica, o por el cariotipo en casos con amniocentesis por indicaciones convencionales. Resultados: Se consiguió asignar el sexo fetal correctamente en el $86,3 \%$ de los fetos. La precisión de la asignación ecográfica del sexo fetal fue mayor en varones que en mujeres (el 90,6\% de los varones fueron asignados correctamente vs el $83,1 \%$ de las mujeres, $p<0,05$ ), y se incrementó con la edad gestacional desde un $72 \%$ entre las 11 y $11+6$ semanas, un $92 \%$ entre las 12 y las $12+6$ semanas, hasta un $95 \%$ entre las 13 y las 13+6 semanas. Conclusión: La determinación ecográfíca del sexo fetal tiene una elevada tasa de precisión a partir de las 13 semanas, lo que sugiere que las pruebas invasivas para la exclusión de enfermedades ligadas al X podrían obviarse cuando se identifica un feto varón a esta edad gestacional. Sin embargo, en fetos identificados como mujeres esta decisión deberá posponerse hasta una edad gestacional más avanzada.

\section{PALABRAS CLAVE: Sexo fetal, ultrasonido, diagnóstico prenatal, ecografía del primer trimestre}

\section{SUMMARY}

Objective: To assess the accuracy of fetal gender determination by ultrasound at 11-14 weeks of gestation in a large cohort of unselected population. Methods: A prospective cross-sectional study was performed in 636 consecutive pregnancies at 11-14 weeks of gestation, attending for first trimester ultrasound screening. The genital region was examined in the mid-sagittal plane to detect the sagittal sign and the direction in which the genital tubercle pointed (cranial for males, caudal for females) both as markers of fetal gender. The clinical confirmation of fetal gender was obtained from telephonic interviews after delivery or from karyotype in cases scheduled to amniocentesis for conventional indications. Results: Fetal gender was correctly determined by ultrasound in $86.3 \%$ of the fetuses. The accuracy of sex assignment was higher in male fetuses than in female fetuses $(90.6 \%$ of the males fetuses vs $83.1 \%$ of the females were correctly assigned, $p<0.05)$ and increased with gestational age from $72 \%$ at $11-11+6$ week's to $92 \%$ at $12-12+6$ week's, and $95 \%$ at $13-13+6$ week's gestation $(p<0.01)$. Conclusion: Prenatal gender assignment by ultrasound has a high accuracy rate at 13 to $13+6$ weeks. These results suggest that invasive testing can probably be performed in fetuses identified as males at this gestational age. However in fetuses identified as females, the decision regarding invasive testing should be postponed until a higher gestational age is achieved.

KEY WORDS: Fetal gender, prenatal diagnosis, ultrasound, first trimester ultrasound 


\section{INTRODUCCIÓN}

La determinación ecográfíca del sexo fetal en el segundo trimestre se fundamenta básicamente en la demostración del pene y escroto en el feto varón y de los labios mayores y menores en el feto mujer. Sin embargo, en edades gestacionales más precoces estos signos no son útiles ya que no existe diferencia significativa en el tamaño del pene o del clítoris antes de la semana 14.

Los avances en la tecnología ultrasonográfica en los últimos años han llevado a sugerir la posibilidad de la determinación del sexo fetal durante el primer trimestre basándose en la dirección en la que apunta el tubérculo genital (1), (craneal en los varones, caudal en las mujeres) o en la identificación del "signo sagital" que determina la presencia de un escotadura caudal en las mujeres o craneal en los varones, cuando se estudia el plano mediosagital (2).

La identificación precoz del sexo fetal por ecografía puede ayudar a prevenir procedimientos invasivos innecesarios en pacientes en riesgo de enfermedades ligadas al cromosoma X, tales como hemofilia o distrofia muscular de Duchene, ya que el diagnóstico invasivo solo sería necesario en embarazos portadores de fetos varones.

Hasta la fecha existen escasos trabajos publicados que valoren la precisión de la determinación ecográfica del sexo fetal durante el primer trimestre (3-11). El propósito de este trabajo es valorar la precisión de la determinación ecográfica del sexo fetal entre las 11-13+6 semanas de gestación en una serie prospectiva y grande de pacientes, así como determinar las variables ecográficas relacionadas con esta precisión.

\section{PACIENTES Y MÉTODO}

La determinación del sexo fetal se realizó de forma prospectiva en una serie consecutiva de 636 gestaciones viables, únicas o múltiples, entre las 11 y 14 semanas, que acudieron para la realización de una ecografía rutinaria de primer trimestre entre enero y julio de 2008. Las exploraciones fueron realizadas por 6 ecografistas diferentes con una máquina Voluson 730 Expert (GE Medical Systems, Kretztechnik, Zipf, Austria) o Accuvix XQ (Medison, Seoul, South Korea). La elección de la vía abdominal o vaginal dependió de la preferencia de cada explorador (82,4\% transabdominal, $17,6 \%$ transvaginal) de cara a obtener la mejor imagen del feto. El tiempo total de exploración no superó los 20 minutos.
La región genital fetal se exploró en un plano mediosagital con el feto en posición neutral (ni flexionada ni extendida) con el fin de determinar la dirección del tubérculo genital (1) (craneal para varones y caudal para mujeres). El "signo sagital" fue valorado de acuerdo con lo descrito por Emerson y cols (2), siguiendo el contorno de la nalga de dorsal a ventral para descubrir una protrusión focal que representa el pene o el clítoris. Un ángulo o escotadura caudal entre el eje de la superficie ventral $y$ el eje del tubérculo indica genitales femeninos, mientras que un ángulo o escotadura craneal indica genitales masculinos (Figuras 1,2 y 3).

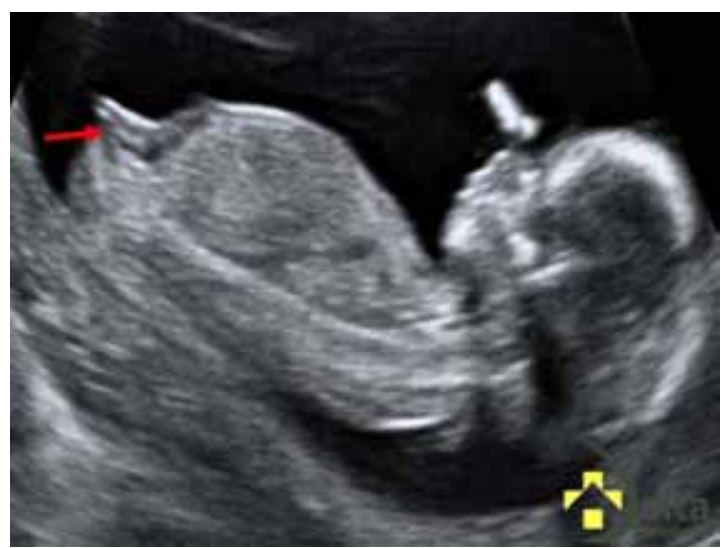

Figura 1. Feto femenino con ángulo convergente del clitoris y presencia de notch caudal.

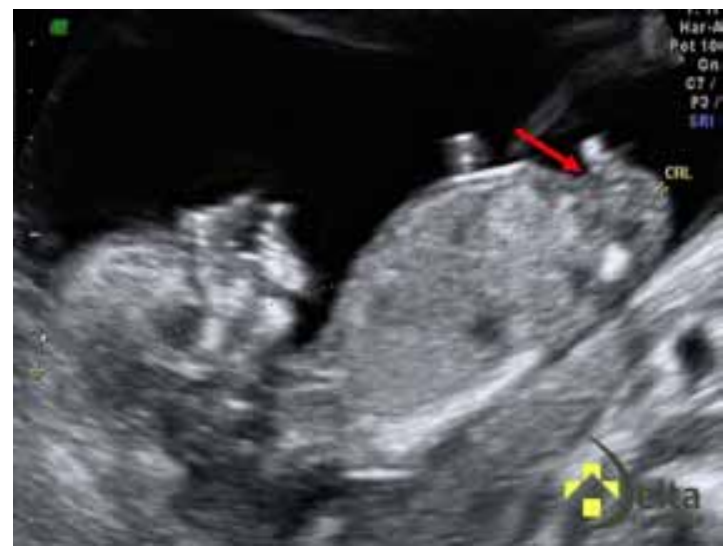

Figura 2. Feto masculino con ángulo del pene y presencia de notch craneal. 


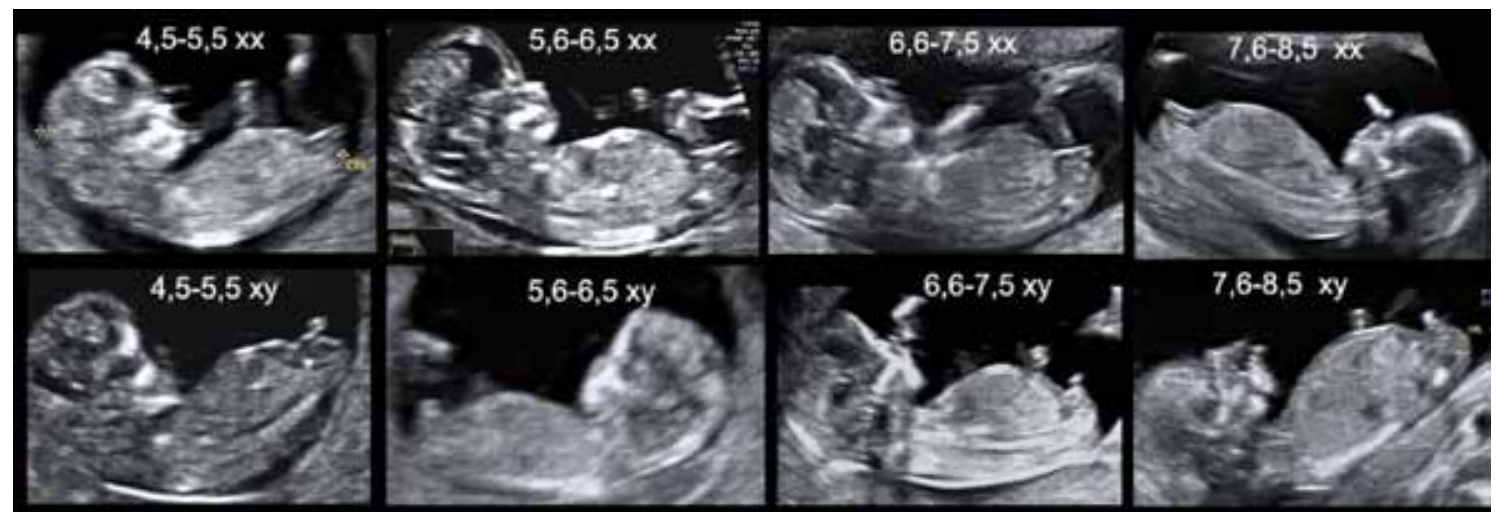

Figura 3. Fetos masculinos y femeninos en diferentes rangos de CRL.

El resultado de los embarazos y la confirmación clínica del sexo fetal al nacimiento se obtuvieron a partir de entrevista telefónica después del parto o a partir del cariotipo en casos programados para amniocentesis por indicaciones convencionales. La tasa de precisión para la determinación del sexo fetal se calculó como la proporción de sexos correctamente identificados respecto al número total de casos en los que se realizó la determinación. El análisis estadístico se realizó mediante el paquete SPSS 12.0 para Windows. Se utilizó el método de la Chi cuadrado para comparar proporciones y un valor $p<0,05$ se consideró como estadísticamente significativo.

\section{RESULTADOS}

La valoración del sexo fetal se intentó en 636 gestaciones, 11 de las cuales eran gemelares, con un total de 647 fetos estudiados. En 40 casos (6,2\%) no se logró una asignación de género debido a posición fetal desfavorable, obesidad materna o a la visualización de un ángulo intermedio del tubérculo genital. En los restantes 607 fetos, la confirmación del sexo fetal fue posible en 598 casos (98,5\%). La edad gestacional media fue de $12+4$ semanas y el CRL medio fue de $61,2 \pm 9,5 \mathrm{~mm}$.

El sexo fetal fue correctamente asignado por ecografía en el $86,3 \%$ de los fetos (516/598). La precisión fue mayor en fetos diagnosticados como varones que en los diagnosticados como mujeres (90,6\% de los varones vs $83,1 \%$ de las mujeres fueron correctamente asignados, $p<0,05$ ) y se incrementó con la edad gestacional, desde un $64,4 \%$ para un CRL entre $45-49 \mathrm{~mm}$, hasta un $100 \%$ para un CRL entre 80-84 mm ( $p<0,05)$ (Tablas I y II). La precisión entre 11-11+6 semanas fue del $71,9 \%$ y se incrementó al $92 \%$ entre $12-12+6$ semanas y al $95 \%$ entre $13-13+6$ semanas $(p<0,01)$ (Tabla III).

Tabla I

PRECISIÓN DE LA DETERMINACIÓN DEL SEXO FETAL SEGÚN LA ASIGNACIÓN INICIAL

\begin{tabular}{lllc}
\hline $\begin{array}{l}\text { Asignación } \\
\text { ecográfica }\end{array}$ & \multicolumn{1}{c}{$\begin{array}{c}\text { Sexo } \\
\text { al nacimiento }\end{array}$} & \multicolumn{1}{c}{ Precisión } \\
\hline Mujer & $344(57,5 \%)$ & $\begin{array}{l}\text { Mujer: } 286 \\
\text { Varón: } 58\end{array}$ & $286 / 344: 83,1 \%$ \\
Varón & $254(42,5 \%)$ & $\begin{array}{l}\text { Mujer: } 24 \\
\text { Varón: } 230\end{array}$ & $230 / 254: 90,6 \%$ \\
Total & & & $516 / 598: 86,3 \%$ \\
\hline
\end{tabular}

Tabla II

PRECISIÓN DE LA DETERMINACIÓN DEL SEXO FETAL EN FUNCIÓN DEL CRL

\begin{tabular}{ll}
\hline $\begin{array}{l}\mathrm{CRL} \\
(\mathrm{mm})\end{array}$ & $\begin{array}{c}\text { Precisión } \\
\mathrm{n}(\%)\end{array}$ \\
\hline $45-49$ & $38 / 59(64,4)$ \\
$50-54$ & $79 / 106(74,5)$ \\
$55-59$ & $94 / 109(86,2)$ \\
$60-64$ & $116 / 122(95,1)$ \\
$65-69$ & $80 / 89(89,9)$ \\
$70-74$ & $53 / 56(94,6)$ \\
$75-79$ & $20 / 21(95,2)$ \\
$80-84$ & $36 / 36(100)$ \\
\hline
\end{tabular}




\section{Tabla III}

\section{PRECISIÓN DE LA DETERMINACIÓN DEL SEXO FETAL EN FUNCIÓN DE LA EDAD GESTACIONAL}

\begin{tabular}{lcccc}
\hline $\begin{array}{c}\text { Edad gestacional } \\
\text { (semanas) }\end{array}$ & $\begin{array}{c}\mathrm{CRL} \\
(\mathrm{mm})\end{array}$ & $\begin{array}{c}\text { Precisión global } \\
(\%)\end{array}$ & $\begin{array}{c}\text { Precisión para } \\
\text { mujeres } \mathrm{n}(\%)\end{array}$ & $\begin{array}{c}\text { Precisión para } \\
\text { varones } \mathrm{n}(\%)\end{array}$ \\
\hline 11 a $11+6$ & $45-55$ & $138 / 192(71,9)$ & $84 / 122(68,9)$ & $54 / 70(77)$ \\
12 a $12+6$ & $56-67$ & $242 / 263(92)$ & $133 / 148(89,9)$ & $109 / 115(94,8)$ \\
13 a $13+6$ & $68-84$ & $136 / 143(95,1)$ & $69 / 74(93,2)$ & $67 / 69(97,1)$ \\
\hline
\end{tabular}

Al comparar el comportamiento del abordaje vaginal o abdominal para la determinación del sexo fetal se encontró que la vía abdominal alcanzó una mayor precisión con un $88,4 \%$ de diagnósticos correctos frente a un $76,2 \%$ de la vía vaginal $(p<0,01)$.

\section{DISCUSIÓN}

En los últimos años se ha propuesto la determinación del sexo fetal durante el primer trimestre. En 1990 Bronshtein y cols (1), describieron que los principales hitos para el diagnóstico de sexo masculino eran el signo de la "cúpula" que representa el escroto y el falo dirigido en sentido craneal (pene), mientras que en el sexo femenino aparecen 2 o 4 líneas paralelas representando los labios y el falo dirigido en sentido caudal (clítoris).

Emerson y cols (2), describieron el "signo sagital" como un marcador ecográfico para la predicción del sexo fetal a partir de la 14ª semana de gestación. En un plano mediosagital, la presencia de una muesca angular en el borde craneal del falo se interpreta como sexo masculino, mientras que en las mujeres esta muesca aparece en el borde caudal del clítoris. Utilizando este signo Mazza y cols (8), alcanzaron una precisión global del $94 \%$ en el primer trimestre y del $100 \%$ a partir de un DBP de $23 \mathrm{~mm}$. Además estudiaron gestaciones conseguidas por FIV e informaron de una precisión absoluta en la identificación del sexo fetal a partir de los 69 días postfertilización correspondientes a 11+6 semanas (12).

Como una alternativa al "signo sagital", Efrat y cols (10), han propuesto la medición del ángulo del tubérculo genital respecto a una línea horizontal trazada sobre la zona lumbosacra. El feto se asigna como sexo masculino cuando el ángulo es superior a $30^{\circ}$, mujer si es inferior a $10^{\circ}$ e indeterminado en los casos con un ángulo intermedio. Utilizando este método refieren una precisión global del 98,6\% que alcanza el $100 \%$ a partir de la $13^{\circ}$ semana de gestación.
Whitlow y cols (6) y Hsiao y cols (11), utilizan un método que combina el estudio del plano sagital y transverso de los genitales y refieren una precisión del $85 \%$ y $91.8 \%$ respectivamente. Pedreira (7) también sugiere el estudio del plano transverso en el que asigna como sexo masculino cuando aparece un tercer punto ecogénico, además de los dos puntos o líneas ecogénicas que se observan en ambos sexos.

El advenimiento de la ecografía 3D ha permitido utilizar esta técnica para la evaluación del sexo fetal. Empleando esta tecnología Lev-Toaff y cols (13), informaron de una precisión del $100 \%$ entre las 11 y las 14 semanas, aunque la limitación de su estudio radica en que sólo 12 fetos en su serie estaban comprendidos en esta edad gestacional. Michailidis y cols (14) refieren una precisión del $85 \%$ utilizando la tecnología 3D.

Según los resultados de nuestra serie podemos afirmar que la ecografía tiene una precisión moderada a baja $(72 \%)$ para la determinación del sexo fetal por debajo de un CRL de $55 \mathrm{~mm}$ y concuerdan con los resultados de otras publicaciones $(3,6,7,11)$ que refieren una proporción de asignación correcta entre el $72 \%$ y el $78 \%$ a las 11 semanas de gestación. Sin embargo para CRLs superiores a $56 \mathrm{~mm}$ (12 semanas), encontramos una tasa de precisión global del $93,1 \%$, que alcanzó un $100 \%$ para un $\mathrm{CRL}$ entre 80 y $84 \mathrm{~mm}$. Whitlow y cols (6), refieren que el sexo fue correctamente asignado en el $86 \%$, $87 \%$ y $92 \%$ de los casos a las 12,13 y 14 semanas. Efrat y cols (10), alcanzaron niveles mayores de precisión, con un $99,6 \%$ de varones y $97,4 \%$ de mujeres correctamente diagnosticados entre las 12 y las 14 semanas. Hsiao y cols (11), informan de tasas de acierto del $92,6 \%$ y $98,9 \%$ a las 12 y 13 semanas respectivamente. Mazza y cols (8), proponen que a partir de un DBP de $22 \mathrm{~mm}$ la precisión es del $99-100 \%$.

En nuestra opinión la ecografía 3D no añade precisión al diagnóstico del sexo fetal, pero las imágenes reconstruidas en superficie nos pueden 
ayudar a observar pequeños detalles del desarrollo de los genitales. Así hemos podido observar como el tubérculo genital acaba en punta en las mujeres y es algo más rectangular en los varones (Figuras 4 y 5$)$.

Existen varios factores que pueden afectar a la correcta identificación del sexo fetal. En primer lugar, la motivación y habilidad relativa del operador, incluso para ecografistas altamente entrenados en ecografía del primer trimestre, es necesaria una

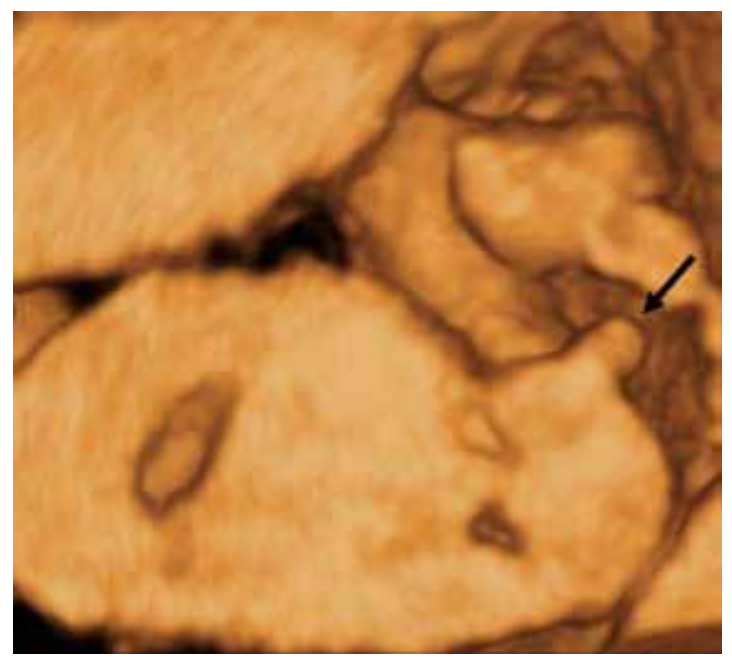

Figura 4. Reconstrucción en superficie de feto masculino con un CRL de $61 \mathrm{~mm}$ con tubérculo genital cuadrangular.

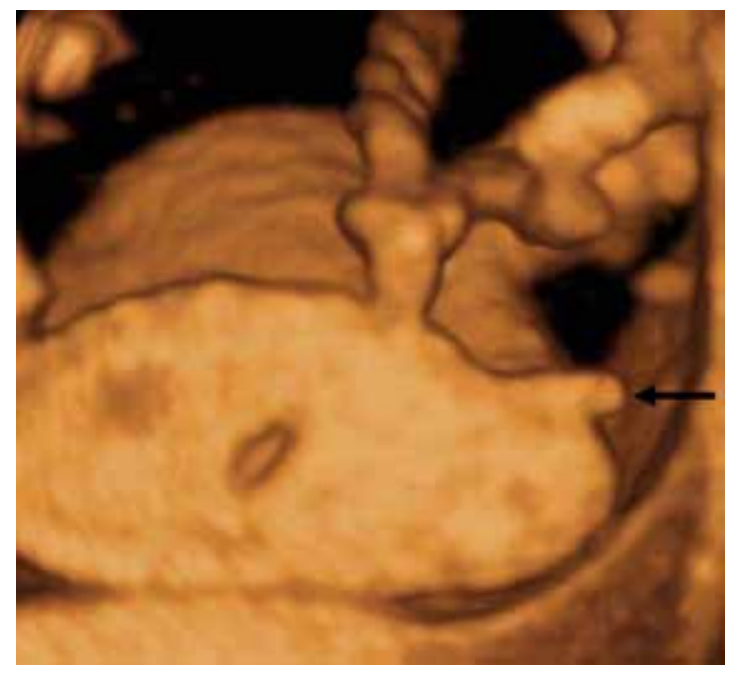

Figura 5. Reconstrucción en superficie de feto femenino con un CRL de $60 \mathrm{~mm}$ con tubérculo genital apuntado. curva de aprendizaje para el estudio del sexo fetal. En segundo lugar, la resolución del transductor empleado. Aunque la resolución de la ecografía vaginal es superior a la abdominal, en nuestro estudio esto no supuso una ventaja ya que la precisión del abordaje abdominal fue mayor. Este hecho puede explicarse porque la obtención de un plano mediosagital perfecto es más fácil con la vía abdominal que con la vaginal, una de cuyas desventajas reconocidas es su limitada maniobrabilidad. Además, el hecho de que el abordaje vaginal fuera utilizado en los casos más desfavorables (obesidad materna, útero en retroflexión, edades gestacionales más precoces) puede contribuir a explicar la menor precisión de esta vía. En tercer lugar, el cambio en el ángulo del tubérculo genital durante la exploración. Se ha sugerido que la dirección en la que apunta el falo masculino es vertical debido a la congestión permanente de los cuerpos cavernosos del pene que produciría una erección mantenida. Sin embargo, este fenómeno puede ser intermitente y común a ambos sexos en el primer trimestre (15). La maduración progresiva del mecanismo responsable de la erección del pene en el varón, junto con el desarrollo del escroto, que al final del primer trimestre obliga al pene a adoptar una dirección vertical, harían que este fenómeno del cambio de ángulo sea menos probable a partir de las 13-14 semanas y que en consecuencia, el diagnóstico del sexo sea más preciso.

La utilidad clínica de la determinación no invasiva del sexo fetal radica en poder evitar el diagnóstico invasivo en gestaciones de riesgo para patologías ligadas al cromosoma $\mathrm{X}$, ya que la identificación de un feto varón indica hemicigosidad para el $X$ y por lo tanto la determinación del cariotipo sólo sería necesaria en estos casos. Además en embarazos con riesgo de hiperplasia suprarrenal congénita, la identificación temprana de un feto varón puede ser ventajosa ya que permitiría la interrupción precoz del tratamiento con dexametasona.

Hoy en día existen dos métodos alternativos para la determinación no invasiva del sexo fetal en el primer trimestre: la ecografía de alta resolución entre las 11-14 semanas y el aislamiento de DNA fetal (free fetal DNA) en plasma materno.

En la actualidad ya existen múltiples trabajos que informan de la precisión de la ecografía en el primer trimestre para el diagnóstico del sexo fetal (Tabla IV). La mayoría informan de una precisión absoluta sólo a partir de semana 13 y en general las tasas de acierto son mayores cuando la asignación es en sentido femenino $(6,7,10,11)$, lo que significa que es más probable que los fetos varones sean incorrectamente diagnosticados (58/288: 
$20,1 \%$ en nuestra serie) y en consecuencia el diagnóstico invasivo erróneamente evitado.

La demostración de que existen niveles significativos de DNA fetal en plasma materno desde edades gestacionales tempranas junto con el rápido desarrollo en la sensibilidad de las técnicas PCR ha permitido la determinación del sexo fetal tan temprano como la 6aㅗ semana de gestación. Existe ya abundante literatura a este respecto y la mayoría acuerda en referir sensibilidades por encima del $90 \%$, muchas cercanas al 100\% (16). Esta elevada precisión aparentemente mayor que la de la ecografía convierte a esta técnica en un método más fiable para la determinación precoz del sexo fetal.

También se ha valorado el uso combinado del análisis de DNA fetal junto con la ecografía. Costa y cols (17), presentan una serie de 131 embarazos de riesgo para enfermedad ligada al cromosoma $X$ valorados mediante análisis de DNA fetal y ecografía en el segundo trimestre demostrando una sensibilidad y especificidad del $100 \%$. Por el contrario
Mazza y cols (18), valoraron 18 casos mediante estudio de DNA fetal entre las 7 y 12 semanas y ecografía a las 12 semanas; mientras que la ecografía alcanzó una precisión del 100\%, la sensibilidad del estudio del DNA fetal solo llegó al 50\%. Hyett y cols (9), evaluaron 30 embarazos con DNA fetal entre las 7 y 12 semanas seguidos de ecografía a las 12-14 semanas; el sexo fetal fue diagnosticado con una precisión absoluta a las 10 semanas y posteriormente confirmado por ecografía, pero lo que es mas importante, un $46 \%$ de las mujeres decidieron no realizarse un test invasivo en base a estos resultados.

Puede concluirse que ambas técnicas no invasivas ofrecen un método fiable de determinación del sexo fetal. Las ventajas del análisis molecular radican en su precocidad y en que es más fiable en aquellas circunstancias que se asocian a desarrollo ambiguo de genitales externos, sin embargo, el diagnóstico de sexo femenino es un diagnóstico de exclusión. La ecografía tiene la desventaja

Tabla IV

PRECISIÓN DE LA ECOGRAFÍA EN EL PRIMER TRIMESTRE PARA LA ASIGNACIÓN DEL SEXO FETAL

\begin{tabular}{|c|c|c|c|c|c|c|c|c|}
\hline \multirow[t]{2}{*}{ Autor } & \multirow[t]{2}{*}{$\mathrm{n}$} & \multirow[t]{2}{*}{$\begin{array}{l}\text { Gestación } \\
\text { (semanas) }\end{array}$} & \multirow[t]{2}{*}{ Técnica } & \multicolumn{3}{|c|}{$\begin{array}{c}\text { Precisión } \\
\text { (cuando intentado) }\end{array}$} & \multirow{2}{*}{$\begin{array}{l}\text { EG para } \\
\text { precisión } \\
\text { del } 100 \%\end{array}$} & \multirow{2}{*}{$\begin{array}{c}\text { Sexo no } \\
\text { asignado } \\
(\%)\end{array}$} \\
\hline & & & & $\begin{array}{l}\text { Varón } \\
(\%)\end{array}$ & $\begin{array}{l}\text { Mujer } \\
(\%)\end{array}$ & $\begin{array}{c}\text { Global } \\
(\%)\end{array}$ & & \\
\hline $\begin{array}{l}\text { Efrat et al } \\
\text { (1999) (3) }\end{array}$ & 157 & $11-13+6$ & TA & 86,7 & 98,7 & 92,4 & $13-13+6$ & 8,7 \\
\hline $\begin{array}{l}\text { Benoit } \\
\text { (1999) (4) }\end{array}$ & 578 & $12-13+6$ & TV & 98,4 & 100 & 98,9 & $13-13+6$ & 37,7 \\
\hline $\begin{array}{l}\text { Mazza et al } \\
\text { (1999) (5) }\end{array}$ & 312 & BPD: 18-29 & TAy/o TV & 91,5 & 95,9 & 93,6 & $13+2$ & 12,5 \\
\hline $\begin{array}{l}\text { Whitlow et al } \\
\text { (1999) (6) }\end{array}$ & 447 & $11-14$ & TAo TV & 87,8 & 84,1 & 85 & NC & 15 \\
\hline $\begin{array}{l}\text { Pedreira } \\
(2000)(7)\end{array}$ & 106 & $11-14$ & TA & NR & NR & 82,1 & $\mathrm{NC}$ & NR \\
\hline $\begin{array}{l}\text { Mazza et al } \\
(2004)(8)\end{array}$ & 2182 & BPD: 18-29 & TA y/o TV & 88,5 & 99,1 & 94,1 & $13+4$ & 9 \\
\hline $\begin{array}{l}\text { Hyett et al } \\
(2005)(9)\end{array}$ & 32 & $10+5-13+2$ & TA & 100 & 100 & 100 & NR & 9,4 \\
\hline $\begin{array}{l}\text { Efrat et al } \\
(2006)(10)\end{array}$ & 613 & $12-13+6$ & TA & 99,6 & 97,4 & 98,6 & $13-13+6$ & 7 \\
\hline $\begin{array}{l}\text { Hsiao et al } \\
(2008)(11)\end{array}$ & 441 & $11-13+6$ & TA & 92,5 & 91,2 & 91,8 & $\mathrm{NC}$ & 11 \\
\hline
\end{tabular}

BPD: diámetro biparietal. NR: no informado. NC: no conseguida. TA: transabdominal. TV: transvaginal. 
de no ser aplicable con fiabilidad hasta la semana 12-13, pero sin embargo, puede aplicarse por igual al diagnóstico de ambos sexos y combinarse para confirmar el diagnóstico molecular de sexo femenino. Tanto genetistas como otros profesionales de la salud que tratan con mujeres con estas patologías, deberían conocer que existen en la actualidad estas opciones de diagnóstico no invasivo del sexo fetal.

Además de la utilidad clínica en casos de enfermedades hereditarias, otra cuestión es la que se refiere al aspecto sociocultural que supone la satisfacción de la curiosidad de los progenitores acerca del sexo de su futuro hijo. En nuestra experiencia la mayoría de los padres desean conocer este dato lo antes posible a pesar de las limitaciones e imprecisión del método. No hay que olvidar que la identificación precoz del sexo fetal puede tener implicaciones de largo alcance en países en desarrollo, donde puede favorecer el aborto selectivo de fetos femeninos con los consiguientes desequilibrios demográficos (19).

\section{CONCLUSIÓN}

A pesar de la elevada proporción de fetos correctamente diagnosticados, la decisión de evitar una prueba invasiva no debe tomarse en fetos con un CRL inferior a $80 \mathrm{~mm}$. El sexo fetal debería ser reconfirmado con posterioridad, preferiblemente en la semana 20. Además, siempre deberá tenerse en cuenta la rara posibilidad de una discordancia entre el sexo fenotípico y genotípico. Se necesitan estudios más amplios, que confirmen las tasas de precisión de la ecografía en el primer trimestre, antes de introducir este método en la práctica clínica rutinaria.

\section{BIBLIOGRAFÍA}

1. Bronshtein M, Rotten S, Yoffe N, Blumenfeld Z, Brandes JM. Early determination of fetal sex using transvaginal ultrasonography: technique and pitfalls. J Clin Ultrasound 1990;18:302-6.

2. Emerson DS, Felker RE, Brown DL. The sagittal sign. An early second trimester sonographic indicator of fetal gender. J Ultrasound Med 1989;8:293-7.

3. Efrat Z, Akinfenwa OO, Nicolaides KH. First trimester determination of fetal gender by ultrasound. Ultrasound Obstet Gynecol 1999;13:305-7.

4. Benoit B. Early fetal gender determination. Ultrasound Obstet Gynecol 1999;13:299-300.
5. Mazza V, Contu G, Falcinelli C, Battafarano S, Cagnacci A, Vito G, Forabosco A, Volpe A. Biometrical threshold of biparietal diameter for certain fetal sex assignment by ultrasound. Ultrasound Obstet Gynecol 1999;13:308-11.

6. Whitlow BJ, Lazanakis MS, Economides DL. The sonographic identification of fetal gender from 11 to 14 weeks of gestation. Ultrasound Obstet Gynecol;13:301-4.

7. Pedreira DAL. In search for the "third point". Ultrasound Obstet Gynecol 2000;15:262-3.

8. Mazza V, Di Monte I, Pati M, Contu G, Ottolenghi C, Forabosco A,Volpe A . Sonographic biometrical range of external genitalia differentiation in the first trimester of pregnancy: analysis of 2593 cases. Prenat Diagn 2004;24:677-84.

9. Hyett JA, Gardener G, Stojikovic-Mikie T, Finning KM, Martin PG, Rodeck CH, Chitty LS. Reduction in diagnostic and therapeutic interventions by non-invasive determination of fetal sex in early pregnancy. Prenat Diagn 2005;25:1111-6.

10. Efrat Z, Perri T, Ramati E, Tugendreich D, Meizner I. Fetal gender assignment by first trimester ultrasound. Ultrasound Obstet Gynecol 2006;27:619-21.

11. Hsiao $\mathrm{CH}$, Wang HC, Hsieh CF, Hsu JJ. Fetal gender screening by ultrasound at 11 to $13+6$ weeks. Acta Obstet Ginecol Scand 2008;87:8-13.

12. Mazza V, Falcinelli C, Paganelli S, Contu G, Mantuano SM, Battafarano SD, Forabosco A, Volpe Al. Sonographic early fetal gender assignment: a longitudinal study in pregnancies after in vitro fertilization. Ultrasound Obstet Gynecol 2001;17:513-6.

13. Lev-Toaff AS, Ozhan S, Pretorius D, Bega G, Kurtz AB, Kuhlman K. Three-dimensional multiplanar ultrasound for fetal gender assignment: value of the mid-sagittal plane. Ultrasound Obstet Gynecol 2000;16:345-50.

14. Michalidis GD, Papageorgiou P, Morris RW, Economides DL. The use of three-dimensional ultrasound for fetal gender determination in the first trimester. $\mathrm{Br} J$ Radiol 2003;76:448-451.

15. Pedreira DAL, Yamasaki A, Czeresnia CE. Fetal phallus "erection" interfering with the sonographic determination of fetal gender in the first trimester. Ultrasound Obstet Gynecol 2001;18:402-4.

16. Avent ND, Chitty LS. Non-invasive diagnosis of fetal sex: utilisation of free fetal DNA in maternal plasma and ultrasound. Prenat Diagn 2006;26:598-603.

17. Costa JM, Benachi A, Gautier E. New strategy for prenatal diagnosis of X-linked disorders. N Engl J Med 2002;346:1502.

18. Mazza V, Falcinelli C, Percesepe A, Paganelli S, Volpe A, Forabosco A. Non-invasive first trimester fetal gender assessment in pregnancies at risk for X-linked recessive diseases. Prenat Diagn 2002;22:919-24.

19. Plaker T. Sex selection in China sees 117 boys born for every 100 girls. BMJ 2002;324:1253. 